\title{
The use of anti-interleukin-1 agents and tumor necrosis factor-alpha inhibitors in renal transplant recipients
}

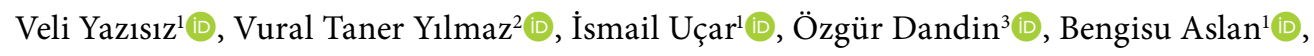

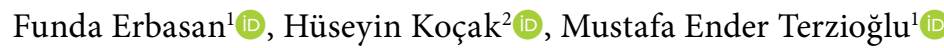 \\ ${ }^{1}$ Department of Internal Medicine, Division of Rheumatology, Akdeniz University School of Medicine, Antalya, Turkey \\ ${ }^{2}$ Department of Nephrology, Akdeniz University School of Medicine, Antalya, Turkey \\ ${ }^{3}$ Department of General Surgery, Akdeniz University School of Medicine, Antalya, Turkey
}

\begin{abstract}
Objectives: The aim of this study was to investigate the efficacy and safety of anti-interleukin-1 (anti-IL-1) agents and tumor necrosis factor-alpha (TNF-a) inhibitors in renal transplant patients.

Patients and methods: Between February 2014 and February 2020, data of 12 renal transplant recipients (9 males, 3 females; median age: 51 years; range, 19 to 70 years) who received anti-IL-1 agents or TNF-a inhibitors for inflammatory diseases in the post-transplant time period and were followed in a single transplant center $(n=12)$ were retrospectively analyzed. A total of 46 cases were reported in the literature, before the data were collected. The overall outcomes of all cases were analyzed in this study.

Results: Thirty-seven patients received anti-IL-1 agents in the post-transplant period. The main indications for anti-IL-1 agents were familial Mediterranean fever (FMF) and amyloidosis (75.7\%). The continuation rate of colchicine treatment in patients with FMF was $85.7 \%$. Anti-IL-1 agents prevented attacks completely in $89.3 \%$ of FMF patients. The number of cases used TNF-a inhibitors among renal transplant patients was lower ( $\mathrm{n}=21$ ). The TNF-a inhibitors were used mainly for inflammatory bowel diseases (57.1\%) and ankylosing spondylitis (33.3\%) and suppressed the disease activity in most of the patients with inflammatory diseases $(72.7 \%)$. Death $(n=3)$ and malignancies $(n=3)$ were reported in patients who received TNF-a inhibitors, but not in patients who received anti-IL-1. The renal outcomes and graft survival rates were satisfactory in patients who received both anti-IL-1 agents and TNF- $\alpha$ inhibitors.

Conclusion: Our results support that anti-IL-1 agents can be used effectively and safely in renal transplant patients. Keywords: Amyloidosis, anti-interleukin-1, familial Mediterranean fever, inhibitors, kidney, transplantation, tumor necrosis factor-alpha.
\end{abstract}

The treatment of chronic inflammatory diseases is a complicated and time-consuming process. In more recent years, different biologics have been developed for the treatment of a variety of conditions. They have different mechanisms of action and bind to different targets of the immune system. ${ }^{1}$ Tumor necrosis factor-alpha $($ TNF- $\alpha$ ) inhibitors have been approved for the treatment of various inflammatory diseases, such as rheumatoid arthritis, juvenile idiopathic arthritis, ankylosing spondylitis (AS), psoriasis, psoriatic arthritis, Crohn's disease, and ulcerative colitis. ${ }^{2}$ They have also been used off-label in the treatment of some rheumatic diseases such as sarcoidosis. ${ }^{2}$ Two anti-interleukin-1 (anti-IL-1) agents, namely IL-1 receptor antagonist anakinra

Received: November 22, 2020 Accepted: December 11, 2020 Published online: January 14, 2021

Correspondence: Veli Yazısız, MD. Akdeniz Üniversitesi Tıp Fakültesi İç Hastalıkları Bilim Dalı, Romatoloji Bilim Dalı, 07059 Kampüs, Antalya, Türkiye. Tel: +90 531 - 3439180 e-mail: drvyazisiz@yahoo.com

\section{Citation:}

Yazısız V, Yılmaz VT, Uçar İ, Dandin Ö, Aslan B, Erbasan F, Koçak H, Terzioğlu ME. The use of anti-interleukin-1 agents and tumor necrosis factor-alpha inhibitors in renal transplant recipients. Arch Rheumatol 2021;36(3):366-374.

(02021 Turkish League Against Rheumatism. All rights reserved.

This is an open access article under the terms of the Creative Commons Attribution-NonCommercial License, which permits use, distribution and reproduction in any medium, provided the original work is properly cited and is not used for commercial purposes (http://creativecommons.org/licenses/by-nc/4.0/). 
and IL-1 beta ( $\beta$ )-blocking agent canakinumab, are effective in controlling the clinical signs and symptoms of a variety of autoinflammatory disorders, including familial Mediterranean fever (FMF). ${ }^{3}$ It has been shown that anti-IL-1 agents reduce or stabilize the amount of proteinuria, thereby preserving renal function in patients with FMF-related amyloidosis. ${ }^{4}$

Renal involvement and renal function disorders are common in patients with rheumatic diseases and are related to poor prognosis. In patients with end-stage renal disease, renal transplantation is the most optimal choice among therapy modalities in terms of survival and quality of life of patients. The use of biologics may be necessary to suppressed rheumatic disease during the post-transplant period in renal transplantation patients. However, severe infections are commonly seen in solid organ transplant recipients due to the excessive use of immunosuppressive drugs. ${ }^{5}$ Biological agents - those having immunosuppressive activity - are also associated with an increased risk of infection. ${ }^{6}$ Infections may develop due to the additional burden of biological agents on immunosuppressive drugs.

Systematic clinical studies about the effectiveness and safety of biological agents during the post-transplant period in solid organ transplant recipients have not yet been conducted. Data on this subject is limited to some case series in the literature..$^{7-9}$ Conducting comparative clinical studies is difficult due to the small number of transplant recipients using biological drugs. In the present study, we aimed to investigate the efficacy and safety of anti-IL- 1 agents and TNF- $\alpha$ inhibitors in renal transplant patients and to evaluate graft survival in renal recipients receiving these drugs.

\section{PATIENTS AND METHODS}

This single-center, retrospective study was conducted at Akdeniz University School of Medicine between February 2014 and February 2020. Medical records of 12 renal transplant recipients (9 males, 3 females; median age: 51 years; range, 19 to 70 years) who received antiIL-1 agents or TNF- $\alpha$ inhibitors for inflammatory diseases in the post-transplant time period and were followed in a single transplant center $(n=12)$ were analyzed. Age, sex, renal disease, indications for biological, Mediterranean fever gene (MEFV) mutations, the type of dialysis, time spent on dialysis before transplantation, time of transplantation, the doses of biological agents and immunosuppressive drugs, durations and outcomes of treatments, such as the activity of inflammatory diseases, side effects, graft, and patient survival were noted. Laboratory data were obtained from the patient files in the hospital electronic database. We screened serum creatinine levels and estimated-glomerular filtration rate (GFR) in the final follow-up visit. The renal outcomes and graft survival were evaluated by serum creatinine levels, GFR, acute/chronic rejection, and reinitiating renal replacement therapy.

The Bath Ankylosing Spondylitis Disease Activity Index (BASDAI) score ${ }^{10}$ was used to evaluate disease activity of AS in the study, and a BASDAI score of $>4$ indicated an active disease. The effectiveness of treatment in FMF patients was analyzed by the reduction in the frequency of FMF attacks.

The safety assessment of biological drugs was made based on the adverse events reported such as infections, skin rash, injection site reactions, liver toxicity, malignancy, and death.

A written informed consent was obtained from each patient. The study protocol was approved by the Ethics Committee of Akdeniz University School of Medicine (No: 1167/11.12.2019). The study was conducted in accordance with the principles of the Declaration of Helsinki.

\section{Review of the literature}

A literature search was carried out for all cases and case series in the English literature containing keywords of transplantation patients receiving biological drugs. The keywords used for the literature search were as follows: "Transplantation", "IL-1Ra", "Anti-TNF- $\alpha$ ", "Canakinumab", "Anakinra", "Rilonacept", "Adalimumab", "Etanercept", "Infliximab", "Certolizumab", "Golimumab" and "Familial Mediterranean Fever". The PubMed, EMBASE, and Web of Science databases (from January 2000 to February 2020) were searched. Our search identified 12 papers ${ }^{8,9,11-20}$ which reported 34 transplant patients treated with anti-IL-1. Two articles ${ }^{19,20}$ 


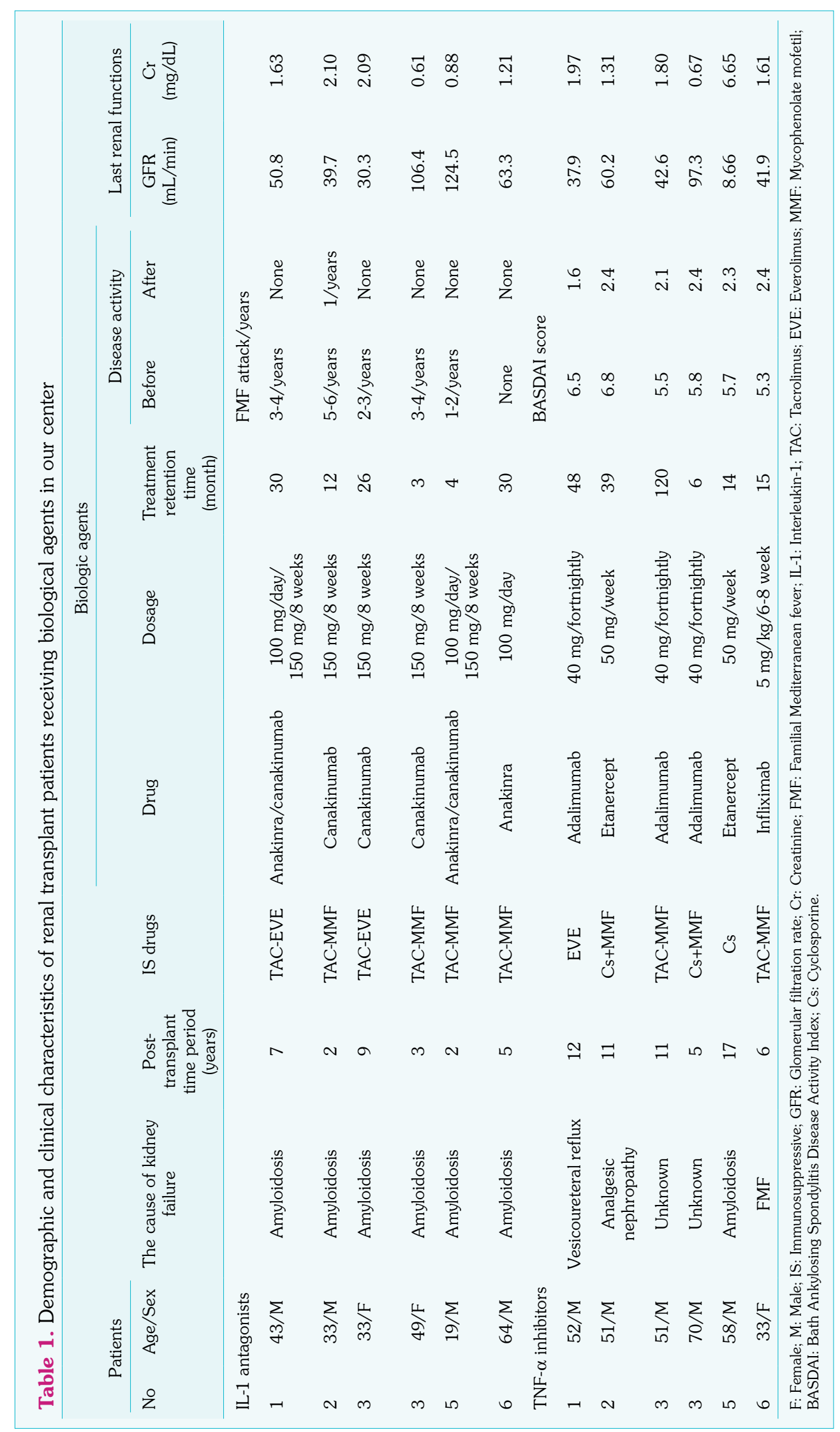


published from the same center with the Ref. 9 were not included in the analysis, since they were thought to be the same cases. There were four articles ${ }^{7,21-23}$ in 15 transplant patients who received TNF- $\alpha$ inhibitors.

\section{Statistical analysis}

Statistical analysis was performed using the SPSS version 13.0 software (SPSS Inc., Chicago, IL, USA). Continuous variables were expressed in mean \pm standard deviation (SD) or median (min-max), while categorical variables were expressed in number and percentage. Continuous variables were compared using the Student's t-test. Categorical variables were compared using the Chi-square test or Fisher's exact test. A $p$ value of $<0.05$ was considered statistically significant.

\section{RESULTS}

In our center, there were 12 renal transplant patients who received biological agents in the post-transplant period. Of these patients, six continued anti-IL-1 treatment for FMF-related amyloidosis, and six received TNF- $\alpha$ inhibitors for the treatment of AS. The patients previously used biological drugs at standard doses recommended for AS (adalimumab $40 \mathrm{mg} /$ fortnightly, subcutaneous; etanercept $50 \mathrm{mg} /$ week, subcutaneous; infliximab $8 \mathrm{mg} / \mathrm{kg} / \mathrm{q} 6 \mathrm{wk}$ or q8wk, intravenous), and FMF (anakinra $100 \mathrm{mg} /$ day, subcutaneous; canakinumab $150 \mathrm{mg} / \mathrm{q} 8 \mathrm{wk}$, subcutaneous). The demographic and clinical characteristics of our patients who underwent renal transplantation and received biological agents are shown in Table 1.

The genetic study for FMF genes was performed in five patients with renal amyloidosis. The majority of the patients had MEFV gene mutations, and the most common mutation was M694V homozygous. Five patients (5/6, 83.3\%) had M694V mutations including M694V in four patients. The patients using anti-IL-1 treatments tolerated treatment very well. The FMF attacks completely disappeared in five of these six patients after anti-IL-1 treatments. One patient experienced one FMF attack per year, which was considered to be a good response in FMF patients. While five patients continued to take colchicine concomitant with anti-IL-1 agents, the other patient withdrew due to side effects. Disease activity was also reduced with TNF- $\alpha$ inhibitors in all AS patients.

There were several causes of renal diseases leading to renal transplantation (Table 1). Hemodialysis was restarted in only one patient due to kidney dysfunction. There were two patients who developed graft rejection. One of them developed chronic humoral rejection and was treated with intravenous immunoglobulin (2 $\mathrm{g} / \mathrm{kg})$, rituximab (375 $\mathrm{mg} / \mathrm{m}^{2}$, single dose), and pulse steroid therapy. In the other patient, $\mathrm{T}$ cell-mediated rejection developed and was treated with anti-thymocyte globulin. There was no graft loss in either of the patients.

The main indications for anti-IL-1 agents were FMF attacks and FMF-related amyloidosis (Table 2). Anti-IL-1 agents were prescribed to treat of FMF attacks and FMF-related amyloidosis in all patients in our center $(n=6)$. In only nine patients (29.0\%) published in the literature, anti-IL-1 agents were prescribed for other indications $(n=6$ gout arthritis, and $n=3$ diagnosed with Muckle-Wells syndrome, chronic infantile neurological cutaneous and articular syndrome, and adult-onset Still's Disease in each). The response rate in the published cases was good at $90.9 \%$. Similarly, the response to anti-IL-1 agents was excellent in our patients. No FMF attack was seen in five of six patients $(83.3 \%)$ in our cohort, after anti-IL-1 agents were initiated. Overall, the rate of the patients prevented from FMF attacks was $89.3 \%$ by using anti-IL-1 agents. The number of attacks were also noted as one to three attacks per year in the other FMF patients. Concomitant with the biological treatment, colchicine was continued in five of six of the patients $(83.3 \%)$ during the post-transplant period in our center. When all FMF patients $(n=22$ from the literature, $n=6$ from our center) were evaluated, the continuation rate of colchicine treatment in FMF patients was 85.7\% ( $\mathrm{n}=24 / 28)$ (Table 2). Any adverse events were observed in $18(48.6 \%)$ patients. The most prevalent adverse events were bacterial and viral infections ( $n=12,32.4 \%)$, and three (8.1\%) patients experienced injection site reactions (Table 3). 


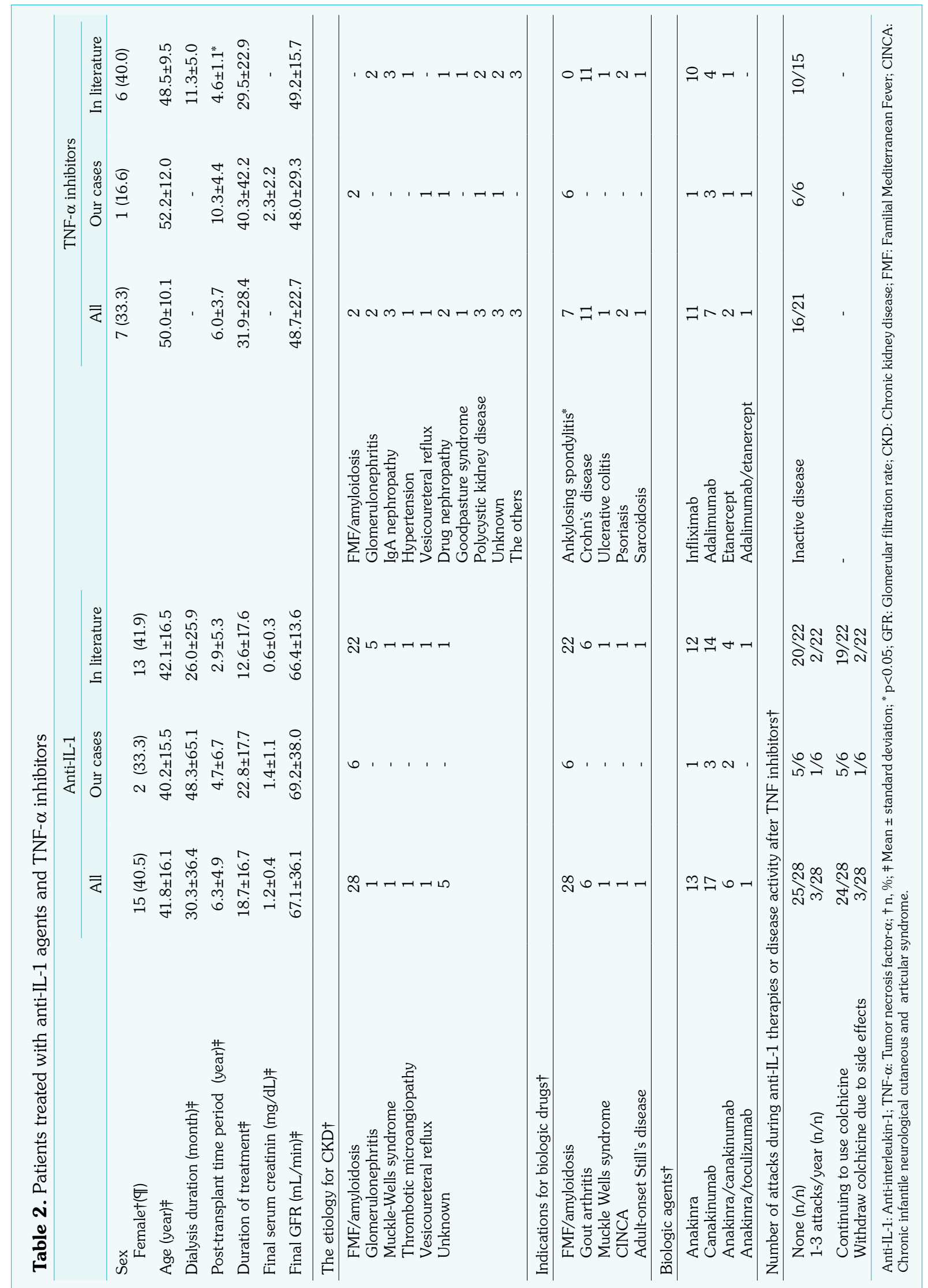


Table 3. The outcomes of patients using anti-IL-1 agents and TNF- $\alpha$ inhibitors

\begin{tabular}{|c|c|c|c|c|c|c|}
\hline & \multicolumn{3}{|c|}{ Anti-IL-1 ( $\mathrm{n}=37)$} & \multicolumn{3}{|c|}{ TNF- $\alpha$ inhibitors $(n=21)$} \\
\hline & $\mathrm{n}$ & $\%$ & Mean \pm SD & $\mathrm{n}$ & $\%$ & Mean \pm SD \\
\hline Age (year) & & & $41.8 \pm 16.1^{*}$ & & & $49.6 \pm 10.2$ \\
\hline $\begin{array}{l}\text { Sex } \\
\quad \text { Female }\end{array}$ & 15 & 40.5 & & 7 & 33.3 & \\
\hline Dialysis duration (month) & & & $30.3 \pm 36.4^{*}$ & & & $9.0 \pm 6.5 \&$ \\
\hline Post-transplant time period (year) & & & $6.29 \pm 4.94^{*}$ & & & $6.2 \pm 3.6$ \\
\hline Duration of biologic agents (month) & & & $18.7 \pm 16.7^{*}$ & & & $32.5 \pm 28.9$ \\
\hline The last serum creatinine (mg/dL) & & & $1.2 \pm 0.4 \dagger$ & & & $2.3 \pm 2.29$ \\
\hline The last GFR (mL/min) & & & $67.1 \pm 36.1 \neq$ & & & $48.8 \pm 20.1$ \\
\hline $\begin{array}{l}\text { Renal outcomes** } \\
\text { Favor } \\
\text { Rejection and hemodialysis }\end{array}$ & $\begin{array}{c}36 \\
1\end{array}$ & & & $\begin{array}{c}14 \\
1\end{array}$ & & \\
\hline $\begin{array}{l}\text { Immunosuppressive agents } \\
\text { TAC-MMF } \\
\text { TAC } \\
\text { MMF } \\
\text { EVE } \\
\text { Cs } \\
\text { AZA } \\
\text { Belatecept }\end{array}$ & $\begin{array}{l}18 \\
34 \\
29 \\
7 \\
3 \\
6 \\
-\end{array}$ & & & $\begin{array}{l}16 \\
15 \\
17 \\
1 \\
3 \\
1 \\
2\end{array}$ & & \\
\hline Any adverse event & 18 & 48.6 & & 11 & 52.4 & \\
\hline $\begin{array}{l}\text { Adverse events and complications } \\
\text { Injection site reactions } \\
\text { Skin rash } \\
\text { Bacterial infections } \\
\text { Viral infections } \\
\text { Liver toxicity } \\
\text { GIS bleeding }\end{array}$ & $\begin{array}{l}3 \\
1 \\
8 \\
4 \\
2 \\
-\end{array}$ & & & $\begin{array}{l}- \\
1 \\
5 \\
3 \\
1 \\
1\end{array}$ & & \\
\hline Deaths & - & - & & 3 & 14.3 & \\
\hline Malignancy & - & - & & 3 & 14.3 & \\
\hline
\end{tabular}

The mean post-transplant time was longer in our patients than the patients in the literature $(p<0.05)$ (Table 2). While the indications for TNF- $\alpha$ inhibitor use were Crohn's disease $(n=11)$, ulcerative colitis $(n=1)$, psoriasis $(n=2)$, and sarcoidosis $(\mathrm{n}=1)$ in the literature, AS was the single indication in our patients $(\mathrm{n}=6)$. Considering all patients, the most preferred TNF- $\alpha$ inhibitor was infliximab. The BASDAI scores decreased with TNF- $\alpha$ inhibitors, from high disease activity to low or moderate disease activity, in AS patients in our center (Table 2). The rate of any adverse events was $52.4 \%(n=11)$. No injection site reactions occurred; however, gastrointestinal system bleeding, malignancies, and even deaths were reported. In the literature, three of 21
(14.3\%) patients died in the TNF- $\alpha$ inhibitor group $^{7}$ and the causes of death were sepsis, cardiovascular disease, and gastrointestinal bleeding. Also, malignancy was reported in three of 21 (14.3\%) patients who received TNF- $\alpha$ inhibitors (Table 3).

The most commonly used immunosuppressive drugs to prevent rejection were mycophenolate mofetil and tacrolimus, in combination, in both groups. There were no significant differences in the distribution of sex, post-transplant time period, the last GFR, and serum creatinine levels. The patients receiving TNF- $\alpha$ inhibitors had a higher mean age, a longer period of drug use, and higher serum creatinine levels than the patients receiving anti-IL-1 agents. Renal outcomes were 
good in both groups (Table 3). The last GFR was higher than $40 \mathrm{~mL} / \mathrm{min} / 1.73 \mathrm{~m}^{2}$ in nine of 12 patients (75.0\%) in our center, and there was only one patient who started hemodialysis again (Table 1).

\section{DISCUSSION}

In the present study, we attempted to share the experiences on use of biological drugs in renal transplant recipients. The data of the patients followed in our center and published in the literature until today were analyzed together to combine our own experiences with the literature. The results provided important data about the topic that is difficult to conduct a systematic clinical study.

To date, colchicine is the most established treatment for FMF, FMF-related amyloidosis, and gout. ${ }^{24,25}$ Owing to its cost-effectiveness and high success rates, this modality is still the first-line treatment for the prevention of disease attacks and associated amyloidosis in FMF patients. ${ }^{24}$ Biological drugs, firstly anti-IL-1 agents, are recommended to treatment-unresponsive patients, defined as being unresponsive to the maximum dose of colchicine. Colchicine has potential toxicity in patients with decreased renal function and, therefore, colchicine dose reduction is necessary. ${ }^{26}$ There is no recommendation on the use of colchicine in patients undergoing kidney transplantation due to the variety of reasons for renal diseases leading to transplantation. Thus, it is challenging to define colchicine resistance and maximum daily dose in renal transplant patients.

Canakinumab and anakinra have been shown to be effective in preventing FMF attacks in colchicine-resistant patients. ${ }^{27,28}$ Furthermore, the regression of FMF-associated amyloidosis was reported with the treatment of anti-IL-1 agents. ${ }^{4}$ In the literature, case reports about the safety and efficacy of anakinra and canakinumab in transplant recipients are limited in the literature. We reported our experience of six patients with an average of 22 months of follow-up and the results of 31 patients published in the literature (mean duration of drug use: 12.6 months). The results of the outcomes of 37 patients showed that, during the follow-up of about 18 months, the use of anti-IL- 1 agents in the post-transplant period was effective in controlling both transplanted kidney function and underlying inflammatory diseases.

The management of patients with rheumatic diseases after organ transplantation is challenging in clinical practice. Physicians can be reluctant to use TNF- $\alpha$ inhibitors concomitant with immunosuppressive drugs during the post-transplant period. Clinical experience is limited, and there are no published guidelines on this subject. The results of this case series showed that $50 \%$ of the patients receiving TNF- $\alpha$ inhibitor therapies did not report any adverse event after treatment. This study provides detailed data regarding the outcomes of renal transplant patients using TNF- $\alpha$ inhibitors and anti-IL-1 agents, based on case reports in the literature.

Infections are the most critical causes of death in patients undergoing organ transplantation, particularly in developing countries. High rates of $\mathrm{BK}$ virus infections were documented in the literature. ${ }^{7}$ In this study, we observed that infections were not a serious concern for these patients.

In the present study, no deaths were reported in those receiving biological therapy. Quinn et al. ${ }^{7}$ reported, however, three deaths in patients receiving TNF- $\alpha$ inhibitors. The causes of death were documented as sepsis, gastrointestinal bleeding, and cardiovascular disease. The overall analysis revealed that malignant diseases $(3 / 21,14.3 \%)$ were diagnosed in the patients who received TNF- $\alpha$ inhibitors. This finding indicated that TNF- $\alpha$ inhibitors, but not anti-IL-1, could be associated with the development of malignancy. However, based on a meta-analysis, there was no evidence of an increased malignancy risk in patients using TNF- $\alpha$ inhibitors. ${ }^{29}$ The common opinion is that malignancy is a frequent event in patients with rheumatic diseases, as a result of factors associated with the risk of developing rheumatic disease. The role of underlying inflammatory diseases that may be also premalignant, such as ulcerative colitis and the effects of intense immunosuppressive use together with TNF- $\alpha$ inhibitors need to be researched to identify the risks of malignancy. The risk of colorectal cancer in inflammatory bowel diseases patients is at least two-fold higher than in the healthy population. ${ }^{30}$ 
The main limitations of this study are its small sample size with a single-center and retrospective design. In addition, the data of the cases reported in the literature are not homogeneous, and the information about the patients is limited to the published data. For instance, remission criteria for inflammatory diseases were not specified in the case reports, and the renal outcomes were based on serum creatinine levels in some cases, but on GFR values in the others. Nonetheless, this descriptive study is the most extensive published series about this rare situation to date.

In conclusion, our study results suggest that anti-IL-1 agents are effective and safe in renal transplant patients with FMF and amyloidosis, and TNF- $\alpha$ inhibitors are also effective in the treatment of inflammatory diseases in renal transplant recipients. The results of long-term graft survival seem to be encouraging for the use of IL- 1 blocking agents and TNF- $\alpha$ inhibitors, leading to the increased use in eligible transplant recipients with the approved indication. However, there is still a need for further studies investigating the safety of TNF- $\alpha$ inhibitors, particularly in terms of mortality and development of cancer, in renal transplant recipients.

\section{Declaration of conflicting interests}

The authors declared no conflicts of interest with respect to the authorship and/or publication of this article.

\section{Funding}

The authors received no financial support for the research and/or authorship of this article.

\section{REFERENCES}

1. Sarzi-Puttini P, Ceribelli A, Marotto D, Batticciotto A, Atzeni F. Systemic rheumatic diseases: From biological agents to small molecules. Autoimmun Rev 2019;18:583-92.

2. Cessak G, Kuzawińska O, Burda A, Lis K, Wojnar M, Mirowska-Guzel D, et al. TNF inhibitors - Mechanisms of action, approved and off-label indications. Pharmacol Rep 2014;66:836-44.

3. Gül A. Approach to the patients with inadequate response to colchicine in familial Mediterranean fever. Best Pract Res Clin Rheumatol 2016;30:296-303.

4. Varan Ö, Kucuk H, Babaoglu H, Guven SC, Ozturk MA, Haznedaroglu S, et al. Efficacy and safety of interleukin-1 inhibitors in familial Mediterranean fever patients complicated with amyloidosis. Mod Rheumatol 2019;29:363-6.

5. Tiago Silva J, López-Medrano F, Aguado JM. Highlights in solid transplant infectious diseases 20152017. Rev Esp Quimioter 2018;31 Suppl 1(Suppl 1):52-5.

6. Caporali R, Crepaldi G, Codullo V, Benaglio F, Monti S, Todoerti M, et al. 20 years of experience with tumour necrosis factor inhibitors: what have we learned? Rheumatology (Oxford) 2018;57(57 Suppl 7):vii5-vii10.

7. Quinn CS, Jorgenson MR, Descourouez JL, Muth $\mathrm{BL}$, Astor BC, Mandelbrot DA. Management of Tumor Necrosis Factor $\alpha$ Inhibitor Therapy After Renal Transplantation: A Comparative Analysis and Associated Outcomes. Ann Pharmacother 2019;53:268-75.

8. Trabulus S, Korkmaz M, Kaya E, Seyahi N. Canakinumab treatment in kidney transplant recipients with AA amyloidosis due to familial Mediterranean fever. Clin Transplant 2018;32:e13345.

9. Özçakar ZB, Keven K, Çakar N, Yalçınkaya F. Transplantation within the era of anti-IL-1 therapy: case series of five patients with familial Mediterranean fever-related amyloidosis. Transpl Int 2018;31:1181-4.

10. Garrett S, Jenkinson T, Kennedy LG, Whitelock H, Gaisford P, Calin A. A new approach to defining disease status in ankylosing spondylitis: the Bath Ankylosing Spondylitis Disease Activity Index. J Rheumatol 1994;21:2286-91.

11. Yildirim T, Yilmaz R, Uzerk Kibar M, Erdem Y. Canakinumab treatment in renal transplant recipients with familial Mediterranean fever. J Nephrol 2018;31:453-5.

12. Kortus-Götze B, Hoyer J. Successful renal transplantation in Muckle-Wells syndrome treated with anti-IL-1 $\beta$-monoclonal antibody. NDT Plus 2011;4:404-5.

13. Moser C, Pohl G, Haslinger I, Knapp S, Rowczenio $D$, Russel $T$, et al. Successful treatment of familial Mediterranean fever with Anakinra and outcome after renal transplantation. Nephrol Dial Transplant 2009;24:676-8.

14. Alpay N, Sumnu A, Calıskan Y, Yazıcı H, Türkmen A, Gül A. Efficacy of anakinra treatment in a patient with colchicine-resistant familial Mediterranean fever. Rheumatol Int 2012;32:3277-9.

15. Hasbal NB, Koc Y, Sevinc M, Unsal A, Basturk T. A familial Mediterranean fever patient with double homozygous mutations treated with anakinra after kidney transplantation. Nefrologia 2020;40:563-4.

16. Celebi ZK, Kucuksahin O, Sengul S, Tuzuner A, Keven K. Colchicine-resistant familial Mediterranean fever in a renal transplantation patient: successful treatment with anakinra. Clin Kidney J 2014;7:219-20. 
17. Mulders-Manders CM, Baas MC, Molenaar FM, Simon A. Peri- and Postoperative Treatment with the Interleukin-1 Receptor Antagonist Anakinra Is Safe in Patients Undergoing Renal Transplantation: Case Series and Review of the Literature. Front Pharmacol 2017;8:342.

18. Loustau C, Rosine N, Forien M, Ottaviani S, Juge PA, Lioté F, et al. Effectiveness and safety of anakinra in gout patients with stage 4-5 chronic kidney disease or kidney transplantation: A multicentre, retrospective study. Joint Bone Spine 2018;85:755-60.

19. Özçakar ZB, Özdel S, Yllmaz S, Kurt-Şükür ED, Ekim M, Yalçınkaya F. Anti-IL-1 treatment in familial Mediterranean fever and related amyloidosis. Clin Rheumatol 2016;35:441-6.

20. Sendogan DO, Saritas H, Kumru G, Eyupoglu S, Sadioglu RE, Tuzuner A, et al. Outcomes of Canakinumab Treatment in Recipients of Kidney Transplant With Familial Mediterranean Fever: A Case Series. Transplant Proc 2019;51:2292-4.

21. Grupper A, Schwartz D, Baruch R, Schwartz IF, Nakache R, Goykhman Y, et al. Kidney transplantation in patients with inflammatory bowel diseases (IBD): analysis of transplantation outcome and IBD activity. Transpl Int 2019;32:730-8.

22. Brokalaki EI, Voshege N, Witzke O, Kribben A, Schadendorf D, Hillen U. Treatment of severe psoriasis with etanercept in a pancreas-kidney transplant recipient. Transplant Proc 2012;44:2776-7.

23. Hanset N, Tsevi MY, Duprez T, Ivanoiu A, Devresse $\mathrm{A}$, Demoulin $\mathrm{N}$, et al. Infliximab for relapsing neurosarcoidosis recurring after kidney transplantation: a case report. Acta Clin Belg 2019:1-3

24. Ozdogan H, Ugurlu S. Familial Mediterranean Fever. Presse Med 2019;48:e61-e76.

25. Pascart T, Richette P. Colchicine in Gout: An Update. Curr Pharm Des 2018;24:684-9.

26. Ozen S, Demirkaya E, Erer B, Livneh A, Ben-Chetrit E, Giancane G, et al. EULAR recommendations for the management of familial Mediterranean fever. Ann Rheum Dis 2016;75:644-51.

27. Roldan R, Ruiz AM, Miranda MD, Collantes E. Anakinra: new therapeutic approach in children with Familial Mediterranean Fever resistant to colchicine. Joint Bone Spine 2008;75:504-5.

28. Ozen S, Bilginer Y, Aktay Ayaz N, Calguneri M. Anti-interleukin 1 treatment for patients with familial Mediterranean fever resistant to colchicine. $\mathrm{J}$ Rheumatol 2011;38:516-8.

29. Seror R, Mariette X. Malignancy and the Risks of Biologic Therapies: Current Status. Rheum Dis Clin North Am 2017;43:43-64.

30. Pohl C, Hombach A, Kruis W. Chronic inflammatory bowel disease and cancer. Hepatogastroenterology 2000;47:57-70. 